\title{
Spark
}

\section{The Patient on the Long Journey Home}

\author{
Stephen C. Hunt, MD MPH \\ Department of Medicine, OEM Program, VA Puget Sound Health Care System, University of Washington, Seattle, WA, USA.
}

$\mathrm{T}$ he first time I saw the patient was as a medical student in 1976 , on one of the old "group wards" at the VA, where a dozen beds were separated by flimsy, pale green curtains. He was 82 and had been admitted for complications after a laryngectomy. In the mechanical drone that emerged from his electrolarynx, he told me the story of his harrowing experiences in Europe during WWI.

The following year I saw him again on a different ward in the VA. He was 60 now, and as we talked about his pending coronary artery procedure he shared that he was one of a small group of Navy corpsman who landed on the beaches of Normandy on June 6 of 1944.

I next encountered the patient during internship. He was in the ER of a community hospital, sleep deprived, shaking with anxiety and having recurrent hallucinations of being back in Vietnam. He was 30 years old and had recently lost his job. His second marriage was unraveling under the weight of his alcoholic self-medicating. It was the late-1970s. It would not be until 1980 that the term PTSD would be used to describe his condition as a discrete disorder, and his "hallucinations" would be re-characterized as flashbacks. ${ }^{1}$ It would be another decade before anyone would begin to take seriously his concerns about exposures to the toxic defoliant Agent Orange during his year in the jungles of Vietnam. ${ }^{2}$

Fifteen years later, I encountered the patient once again. She was in her mid-20's and presenting with a complex constellation of physical symptoms that baffled her providers. When she described her experiences with her National Guard hospital unit during the 1990-91 Gulf War and related her concerns about exposure to chemical weapons, oil fire smoke and a variety of other environmental agents, the picture grew only more challenging. "No one understands," she lamented.

After 2 decades as a primary care provider evaluating and treating veterans with health concerns related to military service, I realized that my work could be considered occupational and environmental medicine. I became board certified in OEM, with a focus on military service as an occupation and combat as an environment that exposes an individual to nearly every health risk imaginable: physical injury, toxic/environmental exposures, temperature extremes, infectious agents, high impact noise, psychological trauma and social disruption. During my fellowship half of my time was spent setting up a clinic that

Published online November 14, 2016 became the prototype for integrated post-deployment clinics in the VA nationwide. ${ }^{3}$ My thesis examined predictors of specific long-term health outcomes in a group of 328 veterans who had been incarcerated as prisoners of war, ${ }^{4}$ demonstrating that certain experiences during incarceration such as torture, solitary confinement, contracting various physical illnesses and having feelings of depression, loneliness and suicidal thoughts all led to worse health outcomes later in life.

This OEM approach to post-combat care, involving biopsychosocial assessment, collaborative care with medical, mental health and social work teams, and a rehabilitation/recovery/reintegration orientation, was rapidly embraced in VA nationally. During an 18-month period between 2008 and 2010, following national and then regional team-based trainings in collaborative post-deployment care, $84 \%$ of VA Centers nationally implemented integrated post-combat care services.

Now I spend my clinical days with primary care residents and OEM Fellows in our Deployment Health Clinic at the VA Puget Sound Medical Center, where we provide integrated post-deployment care for combat veterans returning from Iraq and Afghanistan. Since 2002, approximately 1.2 million of these combat veterans have received such care through VA medical centers across the country. These veterans come home not from war, but with war. War inhabits many veterans as a visceral, malignant and enduring presence in their minds, bodies and spirits. Our mission has been to create a "home" for these veterans, a place where they are heard, appreciated, challenged and supported in their recovery and reintegration. In the Environmental Contaminants Clinic we see veterans with concerns about toxic exposures encountered during military service or deployment, including Agent Orange, ionizing radiation, airborne hazards/burn pit fumes and chemical/ biological warfare agents. We document their exposures, enroll them in appropriate registries, evaluate and address associated health concerns, and connect them with VA resources and services available to them as a result of the exposures.

The patient who has inspired my career has many stories and challenges. With each encounter, I am moved by a new story. A new story that is also an old story, one that has moved me to advocacy. At a briefing to the Office of National Drug Control Policy, about VA efforts to address the national opioid crisis, I reminded officials that in addition to "supply reduction" of opioids, veterans have benefitted from "supply expansion" of 
resources for safe and effective pain care and addictions treatment. I advocated before the National Governors Association for standardized state Prescription Drug Monitoring Programs, which ensure safety in opioid prescribing, and which require not only a healthy VA, but collaboration and partnering within communities and states and nationally. Over the years I have advocated on behalf of veterans before numerous Congressional Hearings, the Institute of Medicine, the Rand Corporation and many professional organizations.

My life as a physician always returns to this patient's story. I continue to encounter this patient every day, feeling ever more humbled by their courage, integrity, honor and sacrifice.

ACKNOWLEDGMENTS: While my comments are my personal perspectives and opinions and do not officially represent the VA, I am a VA employee. I would like to acknowledge the veterans whom I serve, their families who have also "borne the battle" in so many cases and my VA colleagues with whom I share the honor and privilege of this work.

Corresponding Author: Stephen C. Hunt, MD MPH; Department of Medicine, OEM Program, VA Puget Sound Health Care SystemUniversity of Washington, 1660 Columbian Way S., Seattle, WA 98108, USA (e-mail: stephen.hunt@va.gov).

\section{REFERENCES}

1. Diagnostic and Statistical Manual of Mental Disorders (3rd ed., text rev.). Washington, DC: American Psychiatric Association; 1980.

2. H.R. 556 (Agent Orange Act); signed into law by President George H.W. Bush on February 6, 1991.

3. Spelman JF, Burgo L, Hunt SC, Seal KH. Post-deployment care for returning combat veterans. J Gen Intern Med. 2012;27(9):1200-1209.

4. Hunt SC, Orsborn M, Checkoway H, Biggs ML, McFall M, Takaro TK. Later life disability status following incarceration as a prisoner of war. Mil Med. 2008;173(7):613-618. 